\title{
Effects of Genotype Matching of Feline Major Histocompatibility Complex (FLA) Class II DRB on Skin-allograft Transplantation in Cats
}

\author{
Yasuhito KUWAHARA ${ }^{1)}$, Katsuya KITOH ${ }^{1)}$, Rie KOBAYASHI ${ }^{1)}$, Junko IWATA ${ }^{1)}$, Rieko OHNE ${ }^{1)}$, \\ Hitoshi KITAGAWA ${ }^{1)}$ and Yoshihide SASAKI ${ }^{1)}$ \\ ${ }^{1}$ Laboratory of Internal Medicine, Division of Veterinary Medicine, Faculty of Agriculture, Gifu University, 1-1 Yanagido, Gifu 501- \\ 1193, Japan
}

(Received 10 January 2001/Accepted 25 June 2001)

ABSTRACT. In order to confirm the effects of matching of expressed feline major histocompatibility complex (FLA) class II DRB genotype on transplantation immunity in cats, skin-allogeneic transplantation was carried out between cats, in which DRB genes expressed were genotyped by the RT-PCR-RFLP method using group-specific primers. Duration until grafts were rejected was $14.63 \pm 1.69$ days (mean \pm standard deviation) in the pairs that had the same type of subgroups, $7.25 \pm 0.71$ days in the pairs that had one different type of subgroup and $6.88 \pm 0.35$ days in the pairs that had two different types of subgroups. The duration of graft survival in the pairs with the same type of subgroups was significantly longer $(\mathrm{P}<0.01)$ than those in the pairs with different types. Although FLA components involved in transplantation immunity should not only be DRB genes, it was suggested that the expressed FLA-DRB genotype might associate with feline transplantation immunity, and that typing and matching of expressed FLA-DRB genes might be one of the important factors in the control of feline transplantation immunity.

KEY WORDS: DRB gene, feline, FLA, RT-PCR-RFLP method, skin-allograft.

Major histocompatibility complex (MHC) molecules on cell surfaces regulate various immune responses by presenting antigens to T cells [16]. MHC molecules are mainly classified into two families, class I and class II molecules, from their structures and functions [2]. The class I molecules are expressed on almost all nucleated cells, and activate CD8-positive lymphocytes which have cytotoxic activity. The other hand, expressions of the class II molecules are restricted to $\mathrm{B}$ cells, macrophages and activated $\mathrm{T}$ cells, and the molecules present antigen to CD4-positive lymphocytes which facilitate some immune reactions [21]. In humans, the class II molecules include DR, DQ, DP, DN, DO and DM [16]. The $\beta$ chain of DR molecules is encoded by the DRB gene which is the most polymorphic class II gene in humans [11], pigs [7], sheep [15] and dogs [6, 18, 19]. In humans, it is known that the DRB gene consists of 9 loci (DRB1 to 9), 5 of which (DRB2, 6, 7, 8 and 9) are pseudo loci [1]. The functions of DRB antigen are closely related with the type of expressed gene. Actually, it has been reported that the type of DRB1 gene is related with the results of mixed lymphocyte reaction [4], susceptibility to autoimmune diseases $[16,21]$ and percent of 1-year renal graft survival [17]. Thus, the typing of DRB genes has been used in the selection of donor and recipient for renal transplantation in humans [16].

The feline MHC (FLA)-DRB gene also displays an extensive degree of genetic polymorphism [10, 23, 24]. Sixty-six FLA-DRB sequences have been found by PCRsequence-based typing in 45 cats $[10,24]$, and those have been divided into 37 genes and 10 subgroups according to the RFLP pattern by us [10]. To date, 1 to 6 kinds of FLADRB genes per head have been identified [10, 24], so that cats may have more than 3 loci in the DRB gene. However, it remains unknown what functions the expressed DRB genes have in cats. For the typing of transcribed genes, the reverse transcription (RT) method for synthesizing cDNA from RNA is applied $[7,8,12,13]$. In the present study, to confirm the effects of matching of FLA class II DRB genotype on transplantation immunity in cats, the durations of skin-allograft survival were compared among the cat pairs in which the DRB genotypes of cDNA were agreed or disagreed.

\section{MATERIALS AND METHODS}

Genotyping of expressed FLA-DRB gene: Peripheral blood samples were collected from 12 unrelated mix-breed cats ( 8 females and 4 males). Total cellular RNA was extracted from a buffy coat using a commercial kit (SV Total RNA Isolation System, Promega, NY, U.S.A.). An RT reaction for synthesizing cDNA from RNA was performed with a thermal cycler (TaKaRa TP2000, Takara Shuzo Co., Ltd., Shiga); $42^{\circ} \mathrm{C}$ for $30 \mathrm{~min}$ and $99^{\circ} \mathrm{C}$ for $5 \mathrm{~min}$ with a commercial kit (RNA PCR Kit, Takara Shuzo Co., Ltd., Shiga) including AMV Reverse Transcriptase XL (Life Sciences, Inc., FL, U.S.A.). The second exon of FLADRB gene was amplified from cDNA by PCR using groupspecific primers (G1-1, G1-2, G2, G3, G4, G5, G6 and G7) [10] as forward primers, and oligonucleotides for human DRB61A (5'-CCGCTGCACTGTGAAGCT-3') [5] as a common reverse primer [24]. Thermal cycles were performed under the same conditions described in another paper [10]. PCR amplified products were digested with some restriction endonucleases (G1-1: Alu I, Hae III, Bpm I, BstU I and Eae I; G1-2: BssH II, EcoR II, Taq I, Fnu4H I and Eae I; G5: Mae III, BssH II, Bsr I and Dde I; G6: Bsr I, 


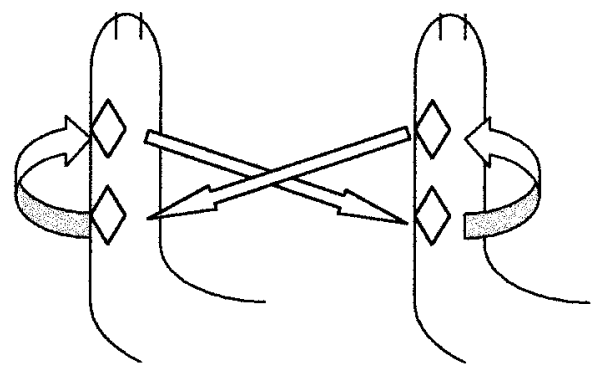

Forearm of cat
Forearm of partner cat

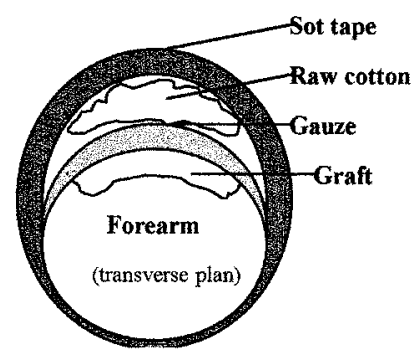

Covering the graft

Fig. 1. Procedure of skin transplantation. Two diamond-shaped skin tissues $(1 \times 2 \mathrm{~cm})$ were excised from the forearms of a cat and a partner cat. Subcutaneous fat was left as much as possible at the graft bed (thick-split-skin graft [3]). The distal graft was transplanted to the proximal graft bed of the partner (allograft). The proximal graft was transplanted to the distal graft bed itself (self-graft) as control. As a result, one party cat was donor as well as recipient, the other party was also donor as well as recipient. These grafts were secured to graft beds with 8-9 simple interrupted sutures of 5-0 nylon, and then covered with sterilized gauze, raw cotton and soft tape for 5 days. Installation of Elizabethcollar and administration of antimicrobial (Enrofloxacin (Baytril, Bayer Corporation, Shawnee Mission, KS, U.S.A.)) were continued during the examination.

BssH II, Eae I, Ava II and Xmn I) [10]. The restriction enzyme-cleaved DNAs were subjected to electrophoresis in 3\% agarose gel (Mupid II, Cosmo Bio Co., Ltd., Tokyo), and visualized by staining with ethidium bromide.

Allogeneic skin-transplantation: Allogeneic skin-transplantation was carried out between cats having the same or different types of cDNA. The procedure of skin-transplantation is shown in Fig. 1. As controls, self-grafts as well as allografts were also transplanted to the graft beds itself. Almost recipient was received skin-grafts from plural donor, and those transplantation was performed at a interval of over one month. The transplantation was carried out in the following order: $3 \Leftrightarrow 4,3 \Leftrightarrow 2,6 \Leftrightarrow 7,2 \Leftrightarrow 6,5 \Leftrightarrow 1,8$ $\Leftrightarrow 9,10 \Leftrightarrow 11,11 \Leftrightarrow 12,9 \Leftrightarrow 10,10 \Leftrightarrow 12,11 \Leftrightarrow 4$ and 4 $\Leftrightarrow 12$. $3 \Leftrightarrow 4$ means the transplantation in which skin-grafts were exchanged between cat No. 3 and No. 4. Biopsies were performed on the grafts involving the edges of the recipient beds when the surfaces of allografts changed to dark-red. Subsequently, the grafts were excised, when the surfaces of the grafts were parched or exfoliated from the graft beds of the recipient. Histopathologic examinations were performed on biopsy specimens and on excised tissues. The samples were stained with hematoxylin and eosin (HE).

Experimental group: The durations until skin-grafts were rejected were compared among the cats in the $\mathrm{A}, \mathrm{B}$ and $\mathrm{C}$ groups. The A group involved 8 pairs that had one same type and two different types of subgroups. In the B group, 8 pairs had two same types and one different type of subgroups. The $\mathrm{C}$ group involved 8 pairs with two to three same types and no different types of subgroups. For comparison of the durations until skin-allografts were rejected, Bonferroni's multiple t-test with 3 comparisons was used.

\section{RESULTS}

Table 1 shows FLA-DRB subgroups genotyped from the cDNA of 12 cats. Two to 3 expressed subgroups were typed in each cat. In the A group, the surfaces of allografts when the covers of grafts were removed (at 5th day) were elastic, and kept their color at transplantation. However, the surfaces of allografts changed to dark-red by the 6th to 7 th day (Fig. 2). The biopsy specimen at that time showed marked ischemic change secondary to thrombus in veins and arteries (Fig. 2). Marked epidermal necrosis and hemorrhages as well as infiltration of mononuclear cells and edema of the dermis and subcutis were observed. These features were more severe on the graft-side. On the other hand, the surfaces of control grafts (self-grafts) at that time kept their elasticity and color at transplantation, and the biopsy-specimens showed only slight hemorrhage and infiltration of mononuclear cells of the dermis and subcutis. Within 1 to 2 days after the surfaces of allografts changed in color, the surfaces of the grafts were parched or exfoliated from the graft beds, and were excised. Histopathologically, infiltration of mononuclear cells extended to the epidermis, and epidermal necrosis progressed markedly on the tissue of the allografts excised. Self-grafts survived. Thus, it was considered that the grafts were rejected when the surfaces of allografts changed to dark-red. The duration of skinallografts survival in the A group was a mean of $6.88 \pm 0.35$ days (standard deviation) (Table 2).

In transplantation of the B group, allografts were rejected by the 6th to 8th day, with a mean of $7.25 \pm 0.71$ days. Histopathologic features of biopsy specimens at rejection were similar to those in the A group. In the $\mathrm{C}$ group, however, the onsets of rejection extended from the 12 th to 17 th day, with a mean of $14.63 \pm 1.69$ days. Biopsy specimens at rejection 
Table 1. FLA-DRB subgroups genotyped from cDNA of 12 cats

\begin{tabular}{rcl}
\hline Cat & \multicolumn{2}{c}{ Subgroupsgenotyped } \\
\cline { 2 - 3 } No. & Number & \multicolumn{1}{c}{ Name } \\
\hline 1 & 3 & $(\mathrm{G} 1-1 \mathrm{a})^{\mathrm{a})},(\mathrm{G} 1-1 \mathrm{~b})^{\mathrm{b})},(\mathrm{G} 5 \mathrm{a})^{\mathrm{c})}$ \\
2 & 2 & $(\mathrm{G} 1-1 \mathrm{a}),(\mathrm{G} 6 \mathrm{~b})^{\mathrm{d})}$ \\
3 & 2 & $(\mathrm{G} 1-1 \mathrm{a}),(\mathrm{G} 5 \mathrm{~b})^{\mathrm{g})}$ \\
4 & 2 & $(\mathrm{G} 1-1 \mathrm{a}),(\mathrm{G} 5 \mathrm{~b})$ \\
5 & 3 & $(\mathrm{G} 1-1 \mathrm{a}),(\mathrm{G} 1-1 \mathrm{~b}),(\mathrm{G} 5 \mathrm{a})$ \\
6 & 2 & $(\mathrm{G} 1-1 \mathrm{a}),(\mathrm{G} 1-2 \mathrm{a})^{\mathrm{e})}$ \\
7 & 2 & $(\mathrm{G} 1-2 \mathrm{a}),(\mathrm{G} 5 \mathrm{c})^{\mathrm{h})}$ \\
8 & 3 & $(\mathrm{G} 1-1 \mathrm{a}),(\mathrm{G} 1-2 \mathrm{a}),(\mathrm{G} 6 \mathrm{a})^{\mathrm{f})}$ \\
9 & 2 & $(\mathrm{G} 1-1 \mathrm{a}),(\mathrm{G} 6 \mathrm{a})$ \\
10 & 2 & $(\mathrm{G} 1-1 \mathrm{a}),(\mathrm{G} 5 \mathrm{~b})$ \\
11 & 2 & $(\mathrm{G} 1-1 \mathrm{a}),(\mathrm{G} 5 \mathrm{~b})$ \\
12 & 3 & $(\mathrm{G} 1-1 \mathrm{a}),(\mathrm{G} 5 \mathrm{~b}),(\mathrm{G} 6 \mathrm{~d})^{\mathrm{i})}$ \\
\hline
\end{tabular}

a) G1-1a is a subgroup which includes 6 FLA-DRB genes, DRB*0103, $* 0107, * 0109, * 0110, * 0111$ and $* 0113$.

b) G1-1b is a subgroup which includes 2 FLA-DRB genes, DRB*0104 and $* 0105$.

c) G5a is a subgroup which includes 3 FLA-DRB genes, DRB*0403, $* 0404$ and *0405.

d) G6b is a subgroup which includes 2 FLA-DRB genes, DRB*0504 and $* 0505$.

e) G1-2a is a subgroup which includes 4 FLA-DRB genes, DRB*0303, $* 0304, * 0305$ and $* 0306$.

f) G6a is a subgroup which includes 2 FLA-DRB genes, DRB*0401 and $* 0402$.

$\mathrm{a} \sim \mathrm{f})$ These definitions are quoted from the reference [10].

g) G5b is a subgroup which includes a FLA-DRB gene, DRB*0501.

h) G5c is a subgroup which includes a FLA-DRB gene, DRB*040103.

i) G6d is a subgroup which includes a FLA-DRB gene, DRB*0511.

showed similar histopathologic features as the A and B groups. In a comparison of the durations of grafts survival, no significant difference was observed between the A and B groups. The duration until rejection in the $\mathrm{C}$ group was significantly longer than that in the $\mathrm{A}(\mathrm{p}<0.01)$ and $\mathrm{B}(\mathrm{p}<0.01)$ groups.

In cases that a recipient was received skin-grafts from plural donor, second graft did not tend to be rejected earlier than first graft at any groups.

\section{DISCUSSION}

In the present study, skin-grafts transplanted between cats having the same types of expressed DRB subgroups (group C) survived for $14.63 \pm 1.69$ days, and this duration was significantly longer than that in cat pairs having some different types (group A and B). Winkler et al. [20] have reported that skin-grafts transplanted between unrelated cats could not survive longer than 10 days. The cats used in the present study were all unrelated, so that we considered that the duration of skin-allograft survival might be prolonged by matching the types of DRB subgroups with the RT-PCR-RFLP method.

In histopathologic examinations of grafts and graft beds, however, there were no qualitative differences among the A, $\mathrm{B}$ and $\mathrm{C}$ groups. The characteristic lesions were infiltration of mononuclear cells and ischemias secondary to formation of thrombus. In human allografts, the vascularization begins to form from the graft bed to the graft around 5 days after transplantation, and mononuclear cells infiltrate into the graft bed and graft. The vasculopathy progresses gradually, then the graft falls into avascular necrosis [3]. In the present study, the histopathologic process of the grafts corresponded to those in studies on humans, so that the histopathologic lesions found in 3 groups could be regarded as the rejection reactions. The prolongation of allograft survival in the $\mathrm{C}$ group might be owing to a lesser degree of allo-antigen stimulation than in the other two groups.

In human transplantation, however, allo-antigen stimulation is mainly influenced by HLA A, B, and C of class I and HLA DR, DP, and DQ of class II [9, 14]. On the other hand, the polymorphism of MHC class I was poor [22] in cats, and there has been insufficient information on FLA class II other than DR genes [23, 24]. Moreover, many factors should be associated with allo-antigen stimulation and graft survival also in cats. Therefore, skin-grafts were finally rejected also in the pairs of the $\mathrm{C}$ group, in which the pairs had the same types of subgroups, and the skin-grafts could survive longer than in the pairs of the A and B groups. Besides, there was no significant difference in durations of skin-graft survival between the cat pairs of the A and B groups, in which the pairs had two and one different types of subgroups, respectively. The typing of DRB genes used in the present study was imperfect, because the subgroups involved some different genes, and it could not be clearly identified which ones in those genes were associated with the skin-graft rejection. Further studies on FLA class II and I will be necessary for suppressing the allo-antigen stimulation on transplantation in cats. However, it was evident that the duration of skinallograft survival was elongated in pairs matched by the RTPCR-RFLP method using group specific primers. This result indicated that the matching of FLA-DRB genes should be one of the important factors in the control of transplantation immunity in cats as well as in humans.

\section{REFERENCES}

1. Andersson, G., Andersson, L., Larhammar, D., Rask, L. and Sigurdardottir, S. 1994. Simplifying genetic locus assignment of HLA-DRB genes. Immunol. Today 15: 58-62.

2. Andersson, L. 1996. Major histocompatibility complex evolution. pp. 1-15. In: The Major Histocompatibility Complex Region of Domestic Animal Species (Schook, L. B. and Lamont, S. J. eds.), CRC Press, Boca Raton, U.S.A.

3. Bhan, A. K., Mihm, M. C. and Dvorak, H. F. 1982. T cell subsets in allograft rejection. J. Immunol. 129: 1578-1583.

4. Bodmer, J. G., Marsh, S. G. E., Alert, E. D., Bodmer, W. F., Dupont, B., Erlich, H. A., Mach, B., Mayr, W. R., Parham, P., Sasazuki, T., Schreuder, G. M. T., Strominger, J. L., Svejgaard, A. and Terasaki, P. I. 1992. Nomenclature for factors of the HLA system, 1991. Tissue Antigens 39: 161-173.

5. Carrington, M., White, M. B., Dean, M., Mann, D. and Lipman, D. J. 1992. The use of DNA heteroduplex patterns to map recombination within the HLA class II region. Hum. Immunol. 33: 114 . 


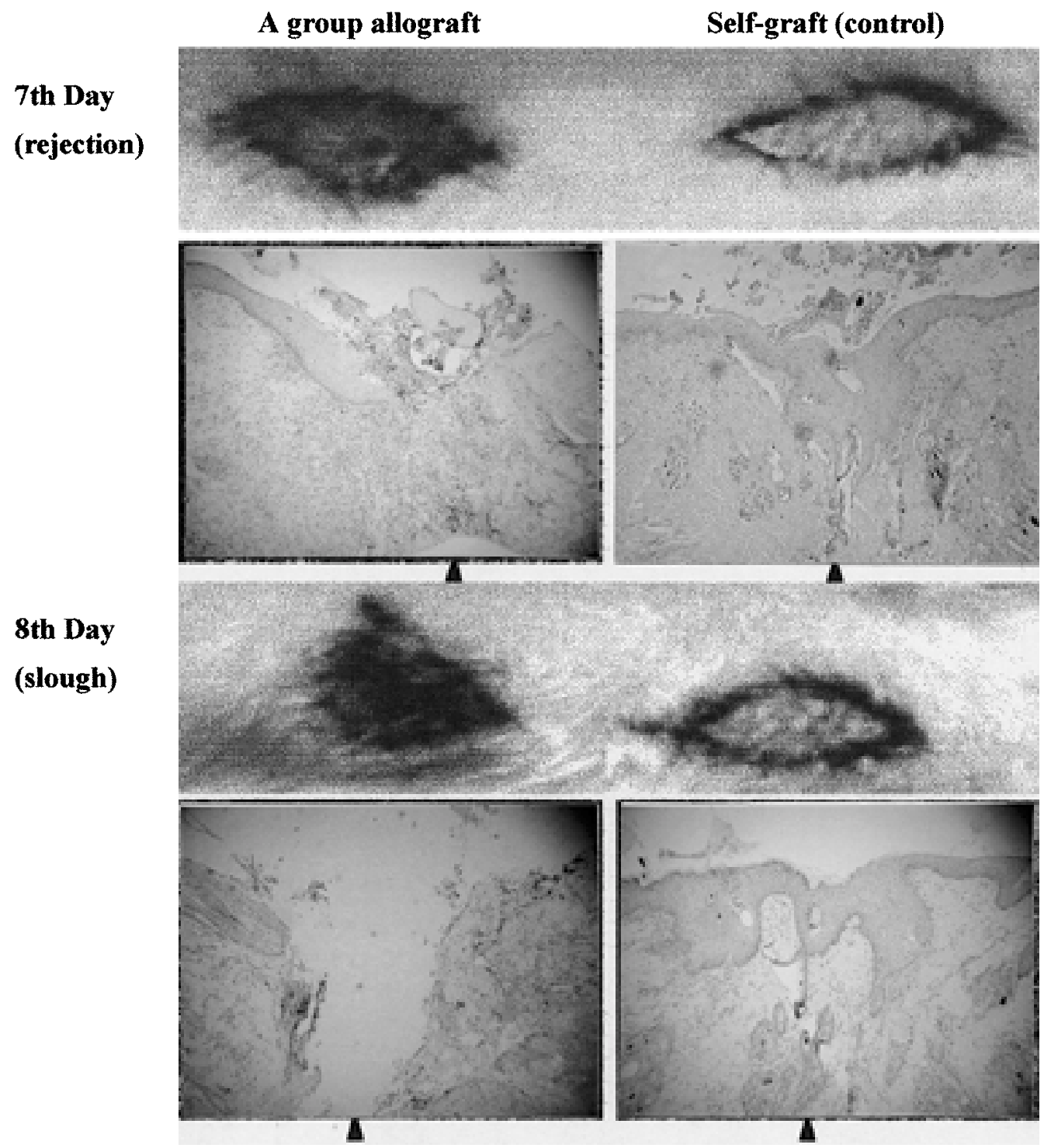

Fig. 2. Gross and microscopic $($ HE. $\times 100)$ findings of skin-allograft and self-graft at 7 th and 8 th day in a case $($ cat No. 6) of A group which was transplanted skin-allograft from cat No. 7. Left half (left from arrow head) of each light microscopic photograph shows the edge of recipient bed, and right half shows allograft or self-graft.

6. Francino, O., Amillis, M. and Sanchez, A. 1997. Canine MHC DRB1 genotyping by PCR-RFLP analysis. Anim. Genet. 28: $41-45$.

7. Hosokawa-Kanai, T., Tanioka, Y., Tanigawa, M., Matsumoto, Y., Ueda, S., Onodera, T. and Matsumoto, Y. 1999. Allelic diversity at class II DRB 1 and DQB loci of the pig MHC (SLA). Immunogenetics 50: 295-300.

8. Kimura, A. 1995. DNA typing of HLA. J. Med. Technol. 39: 271-279 (in Japanese).

9. Koreeda, Y. 1993. Transplantation and HLA allo-antigen stimulus. pp. 35-68 In: Transplantation and Immunity (Inoko, H. ed.), Chugai Igaku Co., Tokyo (in Japanese).

10. Kuwahara, Y., Kitoh, K., Kobayashi, R., Iwata, J., Ohne, R., Hosokawa-Kanai, T., Matsumoto, Y., Kitagawa, H. and
Sasaki, Y. 2000. Genotyping of feline MHC class II DRB second exon by PCR-RFLP method using group-specific primers. J. Vet. Med. Sci. 62: 1283-1289.

11. Marsh, S. G. 1998. HLA class II region sequence, 1998. Tissue Antigens 51: 467-507.

12. Matsumoto, Y., Hosokawa, T. and Onodera, T. 1995. Comparative structural study on major histocompatibility complex class II $\beta$ genes in animals. Bull. Soc. Fr.-Jpn. Sci. Vet. 6: 1116.

13. Sarmiento, U. M., Sarmiento, J. I. and Storb, R. 1990. Allelic variation in the DR subregion of the canine major histocompatibility complex. Immunogenetics 32: 13-19.

14. Schreuder G. M., Hurley, C. K., Marsh, S. G., Lau, M., Maiers, M., Kollman, C. and Noreen, H. 1999. The HLA dictionary 
Table 2. Survival days of skin grafts due to number of same or different subgroups of FLA-DRB in cDNA

\begin{tabular}{|c|c|c|c|c|c|c|}
\hline \multirow[b]{3}{*}{ Group } & \multicolumn{5}{|c|}{ Subgroups } & \multirow{3}{*}{$\begin{array}{c}\text { Day of } \\
\text { rejection }^{\mathrm{d})}\end{array}$} \\
\hline & \multicolumn{2}{|c|}{ Cat No. } & \multirow[b]{2}{*}{ Common } & \multicolumn{2}{|c|}{ Present only in } & \\
\hline & Recipient & Donor & & Recipient & Donor & \\
\hline \multirow{9}{*}{$\mathrm{A}^{\mathrm{a})}$} & 3 & 2 & G1-1a & G5b & G6b & 6 \\
\hline & 2 & 3 & G1-1a & G6b & G5b & 7 \\
\hline & 6 & 7 & G1-2a & G1-1a & G5c & 7 \\
\hline & 7 & 6 & G1-2a & G5c & G1-1a & 7 \\
\hline & 2 & 6 & G1-1a & G6b & G1-2a & 7 \\
\hline & 6 & 2 & G1-1a & G1-2a & G6b & 7 \\
\hline & 9 & 10 & G1-1a & G6a & G5b & 7 \\
\hline & 10 & 9 & G1-1a & G5b & G6a & 7 \\
\hline & & & & & & $6.88 \pm 0.35^{\mathrm{e})}$ \\
\hline \multirow{9}{*}{$\mathrm{B}^{\mathrm{b})}$} & 8 & 9 & G1-1a, G6a & G1-2a & \multirow{4}{*}{$\begin{array}{c}\text { G1-2a } \\
\text { G6d }\end{array}$} & 8 \\
\hline & 9 & 8 & G1-1a, G6a & & & 7 \\
\hline & 11 & 12 & G1-1a, G5b & & & 6 \\
\hline & 12 & 11 & G1-1a, G5b & G6d & & 7 \\
\hline & 10 & 12 & G1-1a, G5b & & \multirow[t]{2}{*}{ G6d } & 8 \\
\hline & 12 & 10 & G1-1a, G5b & G6d & & 8 \\
\hline & 4 & 12 & G1-1a, G5b & & \multirow[t]{3}{*}{ G6d } & 7 \\
\hline & 12 & 4 & G1-1a, G5b & G6d & & 7 \\
\hline & & & & & & $7.25 \pm 0.71^{\mathrm{e})}$ \\
\hline \multirow{9}{*}{$\mathrm{C}^{\mathrm{c})}$} & 3 & 4 & G1-1a, G5b & & & 12 \\
\hline & 4 & 3 & G1-1a, G5b & & & 13 \\
\hline & 5 & 1 & G1-1a, G1-1b, G5a & & & 15 \\
\hline & 1 & 5 & G1-1a, G1-1b, G5a & & & 16 \\
\hline & 10 & 11 & G1-1a, G5b & & & 16 \\
\hline & 11 & 10 & G1-1a, G5b & & & 17 \\
\hline & 11 & 4 & G1-1a, G5b & & & 14 \\
\hline & \multirow[t]{2}{*}{4} & \multirow[t]{2}{*}{11} & \multirow[t]{2}{*}{ G1-1a, G5b } & & & 14 \\
\hline & & & & & & $14.63 \pm 1.69^{\mathrm{e})}$ \\
\hline
\end{tabular}

a) This group involved cat pairs with 1 same type and 2 different types of subgroups.

b) This group involved cat pairs with 2 same types and 1 different type of subgroups.

c) This group involved cat pairs with 2 or 3 same types and no different types of subgroups.

d) Day on which the allograft was rejected.

e) Mean \pm standard deviation.

There was no significant difference in the mean durations of allografts survival between the A and B groups. On the other hand, there were significant differences $(\mathrm{p}<0.01)$ between the $\mathrm{A}$ and $\mathrm{C}$ groups, and between the $\mathrm{B}$ and $\mathrm{C}$ groups.

1999: a summary of HLA-A, -B, -C, -DRB1/3/4/5, -DQB1 alleles and their association with serologically defined HLA-A, -B, -C, -DR and -DQ antigens. Tissue Antigens 54: 409-437.

15. Schwaiger, F. W., Maddax, J., Ballingall, K., Buitkamp, J., Crawford, S. M., Dutia, B. M., Epplen, J. T., Ferguson, E. D., Groth, D., Hopkins, J., Rhind, S. M., Sargan, D., Wetherall, J. and Wright, H. 1996. The ovine major histocompatibility complex. pp. 121-176. In: The Major Histocompatibility Complex Region of Domestic Animal Species (Schook, L. B. and Lamont, S. J. eds.), CRC Press, Boca Raton, U.S.A.

16. Takata, H. 1993. Distinction between self and non-self. pp. 134 In: Transplantation and Immunity (Inoko, H. ed.), Chugai Igaku Co., Tokyo (in Japanese).

17. Ting, A. and Morris, P. J. 1978. Matching for B-cell antigens of the HLA-DR series in cadaver renal transplantation. Lancet. 18: $575-577$.

18. Wagner, J. L., Burnett, R. C. and Storb, R. 1996. Molecular analysis of the DLA DR region. Tissue Antigens 48: 549-553.
19. Wagner, J. L., Burnett, R. C. and Storb, R. 1999. Organization of the canine major histocompatibility complex: current perspectives. J. Hered. 90: 35-38.

20. Winkler, C., Schultz, A., Cevario, S. and O'Brien, S. 1989. Genetic characterization of FLA, the cat major histocompatibility complex. Proc. Natl. Acad. Sci. U.S.A. 86: 943-947.

21. Yata, J. 1995. Transfusion and transplantation. pp. 346-387. In: Textbook of Immunology for Medical Students and Physicians (Yata, J. ed.), Chugai Igaku Co., Tokyo (in Japanese).

22. Yuhki, N., Heidecker, G.F. and O'Brien, S.J. 1989. Characterization of MHC cDNA clones in the domestic cat diversity and evolution of class I genes. J. Immunol. 1429: 3676-3682.

23. Yuhki, N. and O'Brien, S. J. 1988. Molecular characterization and genetic mapping of class I and class II MHC genes of the domestic cat. Immunogenetics 27: 414-425.

24. Yuhki, N. and O'Brien, S.J. 1997. Nature and origin of polymorphism in feline MHC class II DRA and DRB genes. $J$. Immunol. 158: 2822-2833. 